\title{
DYNAMIC HERDING BEHAVIOUR IN THE US STOCK MARKET
}

\section{Muhammad Yasira (D) A. Özlem Önder ${ }^{\mathfrak{B}}$}

\begin{abstract}
This paper employs a dynamic herding approach that takes herding under different market regimes into account. We use daily data on US stock returns for the S\&P 500 ranging from 2006 to 2017. The results of the linear model yield no evidence of herding. However, the findings of switching regression of Bai and Perron (1998) demonstrate evidence of herding during crisis regimes of S\&P 500. The alternative approach of Markov switching also supports these findings.
\end{abstract}

Keywords: Behavioural finance, herding behaviour, cross-sectional dispersions, structural breaks

JEL Classification: G41, G01, G15, C58, C22

\section{Introduction}

The efficient market hypothesis, developed by Fama (1965), argues that in order to hold an optimal portfolio and maximize returns at a given level of risk, investors act in a rational pattern. According to the efficient market hypothesis, prices reflect all of the available information. Therefore, the market as a whole does not deviate from rationality and that is the traditional approach of finance. Contrary to this approach, behavioural finance argues that market participants are exposed to their behavioural biases and emotions when encountering uncertain and risky environments. Such emotions affect an investor's decision making. During the past two decades, a number of studies have been carried out to emphasize the prevalence of unexpected results called anomalies in financial markets. As is well known, such anomalies lead the market to inefficiency.

\footnotetext{
* A previous version of this study was presented at the $7^{\text {th }}$ International Congress of Management, Economy and Policy, 2-3 November 2019, Istanbul, Turkey.

a Department of Management Sciences, COMSATS University Islamabad, Attock Campus Pakistan

b Department of Economics, Ege University, Izmir, Turkey

Email: yasirfw@cuiatk.edu.pk; ozlem.onder@ege.edu.tr
} 
Investors always try to diversify their investments in order to minimize the risk (Markowitz, 1952). However, herding behaviour is one of the anomalies in financial markets defined as a behavioural predisposition that is characterized by trading in the same direction over a period of time by a group of investors (Nofsinger and Sias, 1999).

In such a case, investors irrationally disregard their prior beliefs and private signals and blindly imitate others for a while (Nofsinger and Sias, 1999). According to Caparrelli et al. (2004) investors behave like judges of a beauty contest, which is described by Keynes, as they choose the candidate which may please the majority rather than a beautiful one. Such behaviour of investors makes the asset prices deviate from their fair values, which in turn injects volatility in the market (Blasco et al. 2012). Hence, it is an important point of concern to investigate whether herding behaviour varies across different regimes or not. In order to investigate this phenomenon, linear parameter models are considered in the literature. However, dynamic (time-varying) models are not very common (see, e.g., Balcilar et al., 2013; Klein, 2013). Another shortage of these studies is that they do not use structural change models that allow existence of herding behaviour under different regimes. Therefore, the main objective of the study is to explore the time-varying nature of herding phenomenon using a structural change model developed by Bai and Perron (1998). Also, the time-varying nature of herding behaviour can be investigated using Markov switching (MS) models. The novelty of this study is twofold. Firstly, we estimate a new herding model that incorporates herding under different market regimes with a focus on the US stock market. To the best of our knowledge, this is the first attempt to use the approach of Bai and Perron (1998) to investigate herding in switching regimes for stock markets. Secondly, we compare our findings of the structural change model with the findings of the MS approach. The data employed range from 2006 to 2017, which covers the recent global financial crisis that started with the turbulences of subprime credit and mortgage markets in the USA in late 2007.

The rest of the paper is organised as follows. The second section gives a brief review of the literature. The third section presents the data and methodology used. The fourth section presents the estimation results of the models. The last section concludes the study.

\section{Literature Review}

The literature on herding behaviour in developed markets is rather intensive. However, different methodologies have shown mixed results. For instance, Christie and Huang (1995) used the approach of cross-sectional standard deviation to examine the presence of herd behaviour in the US stock market using both daily and monthly data. They used a linear model to investigate the herding behaviour and found no proof of its existence. Similarly, Gleason et al. (2004) used data on nine sector exchange-traded funds for the US market 
and found no evidence of herding under extreme market conditions. On the other hand, Hwang and Salmon (2004) developed a different approach and conclude the presence of a herd phenomenon for the stock markets of the US and South Korea. Also, the study carried out by Chang et al. (2000) supports the evidence of herding for South Korea, Taiwan and Japan, but their study shows no evidence of herding for the developed markets of the US and Hong Kong. All these studies use a linear model for empirical testing. Recently, Chiang and Zheng (2010) have examined 18 stock markets, including emerging markets. Their study shows strong evidence of herding in some of the advanced and Asian stock markets. However, they reported that there is no such evidence for the US and the Latin American stock markets. Klein (2013) investigates the time variability of herding and shows that behavioural biases determine market prices in turmoil periods. This study used Markov switching, which is a seemingly unrelated model for the US and the euro area. Furthermore, studies carried out by Lakonishok et al. (1992), Grinblatt et al. (1995) and Wermers (1999) found low evidence of herd behaviour among US mutual fund dealers and pension funds. They found herding regarding smaller stocks though. On the other hand, Sias (2004) found that institutional investors follow each other while trading the same stocks and they also consider their own previous trading patterns. Choi and Sias (2009) also found similar results for the institutional industry. Studies carried out recently have reported that herding at the institutional level is more prominent in Japan compared to the US (Kim and Nofsinger, 2005) and that German mutual fund dealers also herd (Walter et al., 2006). They report evidence of herding on bear markets and under extreme market conditions. Later on, the study of Cingl (2013) investigated the impact of different levels of time pressure on herding behaviour and found it insignificant. Recent research conducted by BenSaïda (2017) has reported that herding behaviour prevails in almost all of the sectors of the US stock market during turmoil periods. This study uses the GJR-GARCH model, which provides deep insights into the relationship of herding and idiosyncratic volatility.

As mentioned above, studies of herding behaviour have shown mixed results for developed markets and this would suggest a time-varying nature of herding behaviour. Therefore, we adopt dynamic herding models, which allows us to test the existence of herding behaviour under different regimes.

\section{Data and Methodology}

We obtained daily data on the S\&P 500 index and 500 listed companies from the Thomson Reuters Data stream from 1 January 2006 to 30 May 2017. ${ }^{1}$

1 Data regarding dividend to price ratio and T-bills are collected from https://www.quandl.com and https://finance.yahoo.com. 
In order to test for herding behaviour, cross-sectional standard deviation (CSSD) of asset returns is used as a measure of return dispersion in the literature. A more robust measure called cross-sectional absolute deviation (CSAD) is presented by Chang et al. (2000) as

$$
C S A D_{t}=\frac{1}{N} \sum_{i=1}^{N}\left|R_{i, t}-R_{m, t}\right|,
$$

where $R_{i, t}$ is the $i^{\text {th }}$ asset return at the time $t$, and $R_{m, t}$ is the market return at the time $t$.

\section{Figure 1: Graphs of CSAD and Market Return}
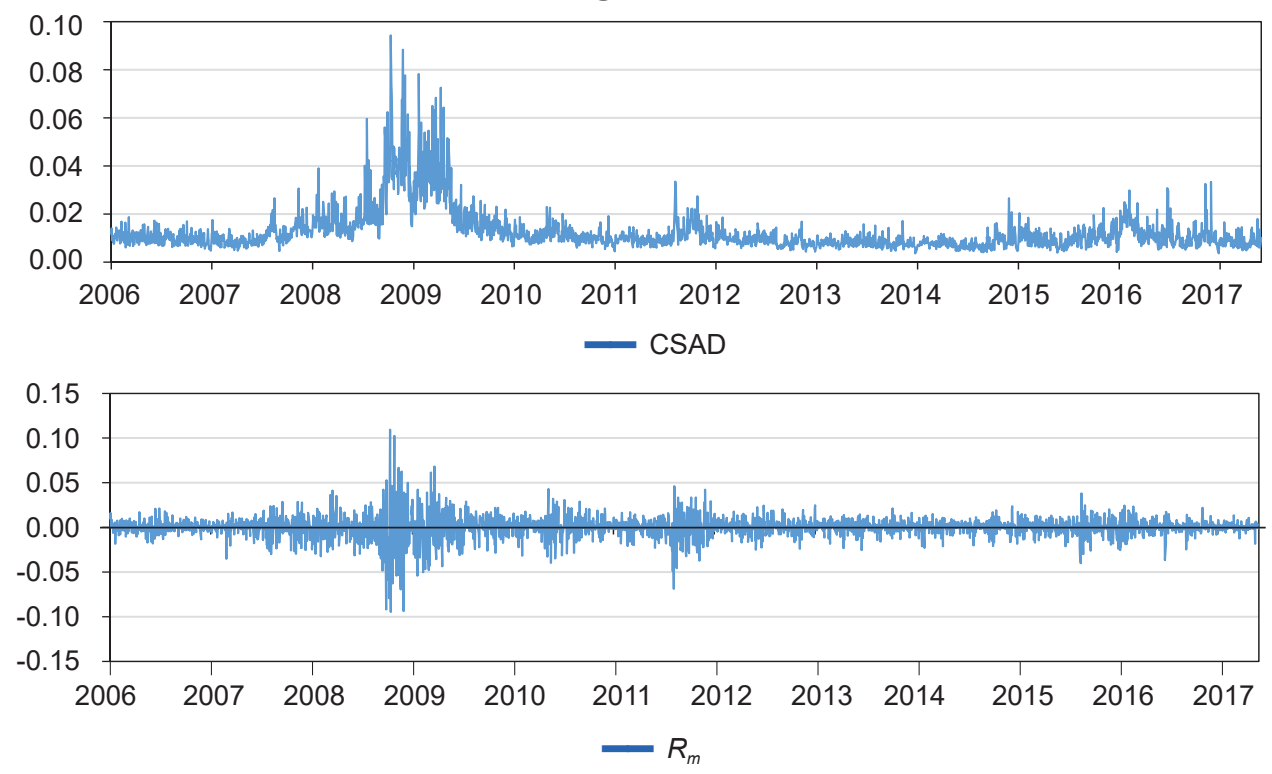

Source: Author's calculation based on data set of S\&P 500

In Figure 1, the plot of $\boldsymbol{C S} \boldsymbol{A} \boldsymbol{D}_{t}$ and $\boldsymbol{R}_{\boldsymbol{m}}$ has shown a transparent picture of the recent global financial crisis of 2008. $\boldsymbol{C S} \boldsymbol{A} \boldsymbol{D}_{t}$ shows high spikes whereas $\boldsymbol{R}_{\boldsymbol{m}}$ shows upward and downward swings for the period considered.

Following Chang et al. (2000), using the conditional version of the capital asset pricing model (CAPM), it is possible to show that CSAD is a linear and increasing function of the market return. The CAPM is presented as:

$$
E_{t}\left(R_{i}\right)=\alpha_{0}+\beta_{i} E_{t}\left(R_{m}-\alpha_{0}\right)
$$

where $\alpha_{0}$ is the risk-free rate of return, $\beta_{i}$ shows the systematic risk of the security $i$. 
Let $\beta_{m}=\frac{1}{N} \sum_{i=1}^{N} \beta_{i}$, then it is possible to show that

$$
A D_{i, t}=\left|\beta_{i}-\beta_{m}\right| E_{t}\left(R_{m}-\alpha_{0}\right)
$$

where $A D_{i, t}$ is the absolute value of the deviation of the expected return of the security $i$ in the period $t$ from the expected return on the portfolio in the period $t$. In this context, the expected CSAD in the period $t$ can be presented as

$$
\operatorname{ECSAD}_{t}=\frac{1}{N} \sum_{i=1}^{N} A D_{i, t}=\frac{1}{N} \sum_{i=1}^{N}\left|\beta_{i}-\beta_{m}\right| E_{t}\left(R_{m}-\alpha_{0}\right) \text {. }
$$

Since $\frac{1}{N} \sum_{i=1}^{N}\left|\beta_{i}-\beta_{m}\right|>0$, there is a linear and increasing relationship between CSAD $_{t}$ and $E_{t}\left(R_{m}\right)$ (see Chang et al., 2000, for details).

As a summary, rational asset pricing models, like the CAPM, suggest a linear and increasing relation between return dispersion and market return. However, in the case of herding behaviour, market participants may react in a more uniform manner during periods of market stress, which results in greater directional similarity in stock returns. For this reason, during extreme market conditions, when the price movement is large, the proportional increase in $C S A D$ would be less. Hence, CSAD and market return would have a nonlinear relationship (Chang et al., 2000) ${ }^{2}$. In order to obtain this relationship, we use the following equation (Economou et al., 2011):

$$
C S A D_{t}=\gamma_{o}+\gamma_{1}\left|R_{m, t}\right|+\gamma_{2} R_{m, t}^{2}+\varepsilon_{t},
$$

where $\varepsilon_{t}$ denotes the error term. The nonlinearity between the CSAD and the average market return is captured by the coefficient $\gamma_{2}$ in Equation 5. The negative and significant value for $\gamma_{2}$ shows the presence of herding behaviour. The existence of this value suggests that extreme market movements lead to greater similarity in individual stock returns.

\subsection{Structural break approach of Bai and Perron}

The structural change approaches have attracted the interest of researchers in this field. Especially Bai and Perron (1998) have developed a new approach that determines unknown structural change in data. Therefore, it is quite useful to estimate the multiple structural variations in a linear parameter model investigated by the least squares.

To elucidate the Bai-Perron approach, we use the following equation to examine herding behaviour in the US stock market.

$2 C S A D_{t}$ and $R_{m, t}$ are used as proxy for the $E C S A D_{t}$ and $E t\left(R_{m}\right)$ as in Chang et al. (2000). 


$$
\begin{array}{ll}
C S A D_{t}=\gamma_{o 1}+\gamma_{11}\left|R_{m, t}\right|+\gamma_{21} R_{m, t}^{2}+\varepsilon_{t}, & t=1, \ldots, T_{1} \\
\cdot & \\
\cdot & \\
C S A D_{t}=\gamma_{0 r}+\gamma_{1 r}\left|R_{m, t}\right|+\gamma_{2 r} R_{m, t}^{2}+\varepsilon_{t}, & t=T_{r}, \ldots, T
\end{array}
$$

where $\left(T_{1}, \ldots, T_{r}\right)$ are the break points and are considered to be unknown; $\varepsilon_{t}$ denotes the error term.

The least-square estimators are obtained by minimizing the residual sum of squares given as

$$
\sum_{i=1}^{r+1} \sum_{t=T_{i-1}+1}^{T_{i}}\left(C S A D_{t}-\gamma_{o i}-\gamma_{1 i}\left|R_{m, t}\right|-\gamma_{2 i} R_{m, t}^{2}\right)^{2}
$$

\subsection{Markov switching model}

As a further support, we apply the MS model by Hamilton (1990) as follows:

$$
C S A D_{t}=\gamma_{0, S_{t}}+\gamma_{1, S_{t}}\left|R_{m, t}\right|+\gamma_{2, S_{t}} R_{m, t}^{2}+\varepsilon_{t},
$$

where $\varepsilon_{t} \sim i i d\left(0, \sigma_{s t}^{2}\right)$ and $S_{t}$ represents a discrete regime variable that has values $0,1,2$ and follows a three-state Markov process. $S_{t}$ is explained as a three-state first-order Markov chain with transition probabilities, $p_{i j}=\operatorname{Pr}\left(S_{t+1}=i \mid S_{t}=j\right)$. Here, $p_{i j}$ shows the probability of staying in the state $i$ at the time $t+1$ given that the market was in the regime $j$ at the time $t$, the values of $i$ and $j$ are $0,1,2 . \sum_{i=0}^{2} p_{i j}=1$ is the satisfying condition for transition probabilities.

The estimation of the MS herding model depends on maximization of the log-likelihood function to find the parameters of the model and transition probabilities. After the estimation process, it is possible to obtain smoothed probabilities (Hamilton, 1990).

\section{Results and Discussion}

The results of the linear and regime-switching models are reported and discussed in detail in this section. 


\subsection{Herding behaviour analysis using linear model}

We use Equation 1 to find out CSAD. In order to estimate the herding model, we first use Equation $5^{3}$. If the coefficient of squared market return $\gamma_{2}$ is found significantly negative, it means that a herding anomaly exists on the market.

Table 1: Herding behaviour using linear models

\begin{tabular}{|c|c|c|c|c|c|c|c|c|}
\hline \multirow[t]{2}{*}{ Equations } & \multicolumn{8}{|c|}{ Parameters } \\
\hline & $Y_{0}$ & $Y_{1}$ & $r_{2}$ & $\theta_{1}$ & $\theta_{2}$ & $\lambda_{1}$ & $\omega_{1}$ & $\omega_{2}$ \\
\hline Equation 5 & 0.009 & $\begin{array}{c}0.444^{* * *} \\
(17.930)\end{array}$ & $\begin{array}{l}2.496^{* * *} \\
(5.700)\end{array}$ & - & - & - & - & - \\
\hline Equation 8 & 0.008 & $\begin{array}{c}0.498^{* * *} \\
(15.068)\end{array}$ & $\begin{array}{l}1.947^{* * *} \\
(3.461)\end{array}$ & - & - & - & - & - \\
\hline Equation 9 & 0.009 & $\begin{array}{c}0.396^{* * *} \\
(10.273)\end{array}$ & $\begin{array}{l}3.212^{* * *} \\
(4.800)\end{array}$ & - & - & - & - & - \\
\hline Equation 10 & -0.025 & $\begin{array}{c}0.245^{* * *} \\
(13.108)\end{array}$ & $\begin{array}{l}1.527^{* * *} \\
(4.852)\end{array}$ & $\begin{array}{c}0.017^{* * *} \\
(51.690)\end{array}$ & $\begin{array}{l}0.001 * * * \\
(16.437)\end{array}$ & - & - & - \\
\hline
\end{tabular}

\section{Equation 11}

\begin{tabular}{l|c|c|c|c|c|c|c|c}
\hline Mean & 0.007 & $\begin{array}{c}0.296^{* * *} \\
(13.766)\end{array}$ & $\begin{array}{c}0.822^{* *} \\
(2.248)\end{array}$ & - & - & $\begin{array}{c}16.391^{* * *} \\
(13.591)\end{array}$ & - & - \\
\hline Variance & - & - & - & - & - & - & $\begin{array}{c}0.1142^{* * *} \\
(12.285)\end{array}$ & $\begin{array}{c}0.864^{* * *} \\
(82.879)\end{array}$ \\
\hline
\end{tabular}

Note: ${ }^{* * *},{ }^{* * *}$ represents the significance at $10 \%, 5 \%$ and $1 \%$ level, $t$-stats are reported in parentheses. Source: Author's calculation based on data set of S\&P 500

Table 1 shows the results of the linear models. Since the coefficient of $\gamma_{2}$ is not found significantly negative, there is no evidence of herding behaviour in the US stock market. We check the robustness of this finding by estimating different linear models. Equation 8 and 9 are used to investigate herding behaviour in up- versus down-market conditions as in Cakan and Balagyozyan (2014).

$$
\begin{aligned}
& C S A D_{t}^{U p}=\gamma_{o}+\gamma_{1}^{U p}\left|R_{m, t}^{U p}\right|+\gamma_{2}^{U p}\left(R_{m, t}^{U p}\right)^{2}+\varepsilon_{t} \\
& C S A D_{t}^{\text {Down }}=\gamma_{o}+\gamma_{1}^{\text {Down }}\left|\gamma_{m, t}^{\text {Down }}\right|+\gamma_{2}^{\text {Down }}\left(R_{m, t}^{\text {Down }}\right)^{2}+\varepsilon_{t},
\end{aligned}
$$

3 In order to determine the order of integration for all the variables $\operatorname{CSAD},\left|R_{m}\right|$ and $R_{m}^{2}$, we applied an ADF unit root test and found all the three series to be stationary at level. Moreover, the PhilipsPerron (1988) test gives the same results. The results are available upon request. 
where $R_{m, t}^{U p},\left(R_{m, t}^{\text {Down }}\right)$ is market return at the time $t$ when the market is up (down). Hence, Equation 8 includes only observations $t$ when market return is positive, while Equation 9 is estimated with observations $t$ when market return is negative. According to the estimation results, we find no evidence of herding in both up- and down-market conditions.

In Equation 10, we use the firm fundamental variable of dividend to price ratio $(D P)$ and the macroeconomic variable of 13-week T-bill rate $(T B)$ as additional explanatory variables to check whether herding is affected by market and firm fundamentals, as suggested by Cakan and Balagyozyan (2014).

$$
C S A D_{t}=\gamma_{o}+\gamma_{1}\left|R_{m, t}\right|+\gamma R_{m, t}^{2}+\theta_{1} D P+\theta_{2} T B+\varepsilon_{t} .
$$

The estimation results reveal no evidence of herding for this model.

As it is suggested by Goyal and Santa-Clara (2003) for the possibility that may capture the relation between idiosyncratic risk and market returns, we control for the impact of volatility by adding a conditional variance term to the mean equation. Hence, we estimate $\operatorname{GARCH}(1,1)$ in the mean model as follows:

$$
\begin{aligned}
& \operatorname{CSAD}_{t}=\gamma_{o}+\gamma_{1}\left|R_{m, t}\right|+\gamma_{2} R_{m, t}^{2}+\lambda_{1} \sigma_{t}^{2}+\varepsilon_{t} \\
& \sigma_{t}^{2}=\omega_{0}+\omega_{1} \varepsilon_{t-1}^{2}+\omega_{2} \sigma_{t-1}^{2},
\end{aligned}
$$

where $\sigma_{t}^{2}$ denotes the conditional variance of the residuals.

The results yield no significant evidence of herding when we incorporate conditional variance in the model by using the $\operatorname{GARCH}(1,1)$ process.

As a summary, the linear models provide no evidence of herding behaviour.

\subsection{Herding behaviour analysis using Bai-Perron approach}

In this part, we discuss the estimation results related to the Bai-Perron approach for the US stock market ${ }^{4}$. In order to determine the number of breaks, Bai and Perron $(1998,2003)$ propose three tests:

- the $\operatorname{Sup} F_{t}(k)$ test of the null hypothesis of no structural break against the alternative of a fixed number of breaks $(k)$;

- the Double Max test having a null hypothesis of no structural break against the alternative of unknown number breaks given some upper bound $R(1 \leq r \leq R)$, i.e. UD Max and WD Max tests; and

4 Estimations were performed using EViews. 
- the Sequential Sup $F_{T}\left(\frac{l+1}{l}\right)$ test of the null hypothesis of $l$ breaks against the alternative of $l+1$ breaks.

Table 2: Tests for determination of breaks

\begin{tabular}{|c|c|c|c|c|c|c|}
\hline \multicolumn{5}{|c|}{ Sup $F_{T}(k)$ test } & \multicolumn{2}{|c|}{ Double Maximum tests } \\
\hline $\operatorname{Sup} F_{T}(1)$ & $\operatorname{Sup} F_{T}(2)$ & $\operatorname{Sup} F_{T}(3)$ & $\operatorname{Sup} F_{T}(4)$ & Sup $F_{T}(5)$ & UD Max & WD Max \\
\hline $907.280^{* * *}$ & $1,100.600 * * *$ & $756.700^{* * *}$ & $596.200^{* * *}$ & $476.990 * * *$ & $1,100.600^{* * *}$ & $1,390.790^{* * *}$ \\
\hline \multicolumn{7}{|c|}{ Sequential Sup $F_{T}\left(\frac{l+1}{l}\right)$ test } \\
\hline $\operatorname{Sup}_{(1 / 0)} F_{T}$ & $\operatorname{Sup}_{(2 / 1)} F_{T}$ & $\operatorname{Sup}_{(3 / 2)} F_{T}$ & $\underset{(4 / 3)}{\operatorname{Sup}} F_{T}$ & $\underset{(5 / 4)}{\operatorname{Sup}} F_{T}$ & - & - \\
\hline $907.280^{* * *}$ & $946.682^{* * *}$ & $43.691^{* * *}$ & $58.391^{* * *}$ & 0.000 & - & - \\
\hline
\end{tabular}

Note: ${ }^{*},{ }^{*},{ }^{* * *}$ represents significance at the $10 \%, 5 \%$ and $1 \%$ level.

Source: Author's calculation based on data set of S\&P 500

We use the Bai and Perron estimation approach for our model with unknown multiple structural breaks. We allow up to 5 break points and trimming of $15 \%$ for the US stock market. The related output is presented in Table 2. The Sup $F_{T}(\mathrm{k})$ test and the Double Maximum tests (UD Max and WD Max) show that there exists at least one break on the considered market. Hence, in all tests the null hypothesis of no breaks is strongly rejected. The sequential Sup $F_{T}\left(\frac{l+1}{l}\right)$ test reported in the same table also shows that Sup (4/3) is highly significant but $\operatorname{Sup} F_{T}(5 / 4)$ is insignificant for the US stock market. Hence, we decide on the basis of the sequential Sup $F_{T}$ that the number of breaks is four.

Table 3 shows the estimation results of the Bai and Perron approach to examine herding in different regimes.

Our results show that there are four break points for the whole data set, i.e., 5 regimes. The coefficient of squared market return $\left(\gamma_{2}\right)$ for regimes 1,4 and 5 is positive and insignificant. However, in regime 3 , it is significantly positive at $1 \%$. Furthermore, it is significantly negative in the case of regime 2 . The results indicate that regime 2 turns out to be the crash regime. Figure 1 also depicts the high volatility of market return during this regime. The mean return of the crisis regime (regime 2) is -0.0006 and the standard deviation is 0.0233. This regime started in early 2008 and ended in late September 2009, covering the recent global financial crisis. Since $\gamma_{2}$ is significantly negative, herding prevails 
during the crisis period. Bekiros et al. (2017) also find evidence of herding on the US market in the earlier crisis period using the quantile approach. Our findings are also consistent with the studies of Christie and Huang (1995); Chang et al. (2000); Demirer et al. (2010) and Chiang and Zheng (2010), who argue that herding is more likely to prevail during market losses. Gleason et al. (2004) and Tan et al. (2008) also argue that chances of herding anomaly are also high during unusual informational flows and high volatility. Furthermore, this empirical finding can be justified by under- and overconfidence of investors during varying market conditions, as Hwang and Salmon (2004) state that it might be possible that market participants lose their confidence when facing uncertain and highly volatile (large swings) market conditions.

Table 3: Estimates of herding model using Bai-Perron approach

\begin{tabular}{|c|c|c|c|}
\hline \multirow[b]{2}{*}{ Coefficients } & \multirow{2}{*}{$\begin{array}{c}\text { Trim \% and Max } \\
\text { Number of breaks } \\
15 \% \text { and } 5 \\
V_{1}\end{array}$} & \multicolumn{2}{|c|}{$\begin{array}{c}\text { Break dates } \\
\text { (16 Jan 2008) (1 Oct 2009) } \\
\text { (8 Aug 2012) (11 Sep 2015) }\end{array}$} \\
\hline & & $r_{2}$ & Herding \\
\hline $\begin{array}{l}\text { Regime } 1 \\
1 / 02 / 20061 / 15 / 2008\end{array}$ & $\begin{array}{c}0.069 \\
(0.723)\end{array}$ & $\begin{array}{c}5.651 \\
(1.433)\end{array}$ & No \\
\hline $\begin{array}{l}\text { Regime } 2 \\
1 / 16 / 2008 \text { 9/30/2009 }\end{array}$ & $\begin{array}{l}0.669^{* * *} \\
(19.241)\end{array}$ & $\begin{array}{l}-1.532 * * * \\
(-3.355)\end{array}$ & Yes \\
\hline $\begin{array}{l}\text { Regime } 3 \\
10 / 01 / 20098 / 07 / 2012\end{array}$ & $\begin{array}{l}0.102^{* *} \\
(2.078)\end{array}$ & $\begin{array}{l}3.661^{* * *} \\
(2.865)\end{array}$ & No \\
\hline $\begin{array}{l}\text { Regime } 4 \\
8 / 08 / 20129 / 10 / 2015\end{array}$ & $\begin{array}{r}0.132^{*} \\
(1.770)\end{array}$ & $\begin{array}{c}0.951 \\
(0.307)\end{array}$ & No \\
\hline $\begin{array}{l}\text { Regime } 5 \\
9 / 11 / 2015 \text { 5/30/2017 }\end{array}$ & $\begin{array}{c}0.166 \\
(1.508)\end{array}$ & $\begin{array}{c}7.895 \\
(1.577)\end{array}$ & No \\
\hline$R^{2}$ & 0.661 & - & - \\
\hline
\end{tabular}

Note: ${ }^{*}, * * * * *$ represents significance at the $10 \%, 5 \%$ and $1 \%$ level, $t$-stats are reported in parentheses. Source: Author's calculation based on data set of S\&P 500

\subsection{Herding behaviour analysis using Markov switching model}

In this section, we discuss the MS approach in detail. First, we apply model selection tests to be sure among linear and regime-switching models. In order to identify a suitable model, we use the LR test, which follows approximately Chi-Square distribution under the null hypothesis. Table 4 reports the results of the model selection test ${ }^{5}$.

$5 \quad$ Estimations were performed using OxMetrics. 


\begin{tabular}{c|c|c|c}
\hline $\begin{array}{c}\mathbf{H}_{\mathbf{0}}: \text { Linear } \\
\mathbf{H}_{\mathbf{1}}: \mathbf{M S}(2)\end{array}$ & $\begin{array}{c}\mathbf{H}_{\mathbf{0}}: \text { Linear } \\
\mathbf{H}_{\mathbf{1}}: \mathbf{M S H}(\mathbf{2})\end{array}$ & $\begin{array}{c}\mathbf{H}_{\mathbf{0}}: \text { Linear } \\
\mathbf{H}_{\mathbf{1}}: \mathbf{M S}(\mathbf{3})\end{array}$ & $\begin{array}{c}\mathbf{H}_{\mathbf{0}}: \text { Linear } \\
\mathbf{H}_{\mathbf{1}}: \mathbf{M S H}(\mathbf{3})\end{array}$ \\
\hline $3,127.94^{* * *}$ & $\begin{array}{c}4,716.6^{* * *} \\
(0.000)[0.000]\end{array}$ & $\begin{array}{c}3,989.24^{* * *} \\
(0.000)[0.000]\end{array}$ & $\begin{array}{c}5,549.42^{* * *} \\
(0.000)[0.000]\end{array}$ \\
\hline $\mathbf{H}_{\mathbf{0}}: \mathbf{M S ( 2 )}$ & $\mathbf{H}_{\mathbf{0}}: \mathbf{M S ( 2 )}$ & $\mathbf{H}_{\mathbf{0}}: \mathbf{M S H}(\mathbf{2})$ & $\mathbf{H}_{\mathbf{0}}: \mathbf{M S}(\mathbf{3})$ \\
$\mathbf{H}_{\mathbf{1}}: \mathbf{M S H}(\mathbf{2})$ & $\mathbf{H}_{\mathbf{1}}: \mathbf{M S}(\mathbf{3})$ & $\mathbf{H}_{1}: \mathbf{M S H}(\mathbf{3})$ & $\mathbf{H}_{\mathbf{1}}: \mathbf{M S H}(\mathbf{3})$ \\
\hline $1,588.66^{* * *}$ & $861.3^{* * *}$ & $832.82^{* * *}$ & $1,560.18^{* * *}$ \\
$(0.000)[0.000]$ & $(0.000)[0.000]$ & $(0.000)[0.000]$ & $(0.000)[0.000]$ \\
\hline
\end{tabular}

Note: The linear model is the herding regression model using Equation (2). MS(s) represents the MS model with regime-independent variance $\varepsilon_{t} \sim i i d\left(0, \sigma^{2}\right)$ and $\mathrm{MSH}(\mathrm{s})$ is the MS model with regime-specific variance, $\varepsilon_{t} \sim$ iid $\left(0, \sigma_{\text {st }}{ }^{2}\right)$. Test statistics are calculated using the Likelihood Ratio (LR) test. Respected Chi-Square $p$-values are reported in parentheses and $p$-values of Davies (1987) are presented in square brackets. $* * * * * *$ represents significance at the $10 \%, 5 \%$ and $1 \%$ level.

Source: Author's calculation based on data set of S\&P 500

According to the table, the linear model is strongly rejected at the $1 \%$ level of significance. Both the $p$-values based on the conventional Chi-Square distribution and the approximate upper bound for the significance level of the LR statistic as derived by Davies (1987) are reported in Table 4 above. Hence, the MS model is found to be appropriate for further proceedings.

We also conduct tests to determine the number of regimes. We consider regimeindependent variance models MS(s) and regime-specific variance models MSH(s), where $s$ denotes the number of regimes. In all of the cases, the null hypothesis is rejected and finally MSH (3) is found to be a suitable model for our data set. We present the results of the Markov switching-regime specific-variance model in Table 5.

As can be seen from Table 5, there exist three regimes for the US stock market. The intercept term $\left(\gamma_{0}\right)$ and the coefficient of absolute $R_{m}$ are reported in the second and third columns, respectively. They are positive and significant at the $1 \%$ level for all of the three regimes. The coefficient $\gamma_{2}$ is found to be highly significant for all of the three regimes. However, its sign is negative only for regime 3.

We could not find any evidence of herding in regimes 1 and 2 , as $\gamma_{2}$ is non-negative for these regimes. However, it is negative and significant for regime 3. Hence, there is strong evidence of herding for the considered regime. Moreover, this regime covers the period of the recent global financial crisis, which can also be seen clearly from Figure 2, which shows smoothed probabilities and covers the financial crisis period from late 2007 to mid-2009. Our findings from the MS and the Bai and Perron approach 
report strong evidence of prevalence of herding in the US stock market during the crisis period. This finding is similar to those of Christie and Huang (1995) and Chang et al. (2000). They argued that there is a clear chance for investors to mimic one another under high and extreme market conditions.

Table 5: Estimates of herding model using MSH (3)

\begin{tabular}{|c|c|c|c|c|c|}
\hline \multirow{2}{*}{ Regime } & \multicolumn{3}{|c|}{ Coefficients } & \multirow{2}{*}{ Sigma } & \multirow{2}{*}{ Herding } \\
\hline & $\gamma_{0}$ & $v_{1}$ & $v_{2}$ & & \\
\hline 1 & $\begin{array}{l}0.008^{* * *} \\
(87.623)\end{array}$ & $\begin{array}{l}0.064^{* * *} \\
(3.366)\end{array}$ & $\begin{array}{l}3.212^{* * *} \\
(4.371)\end{array}$ & $\begin{array}{l}0.002^{* * *} \\
(43.926)\end{array}$ & No \\
\hline 2 & $\begin{array}{l}0.017^{* * *} \\
(36.735)\end{array}$ & $\begin{array}{l}0.095^{* * *} \\
(2.783)\end{array}$ & $\begin{array}{l}3.144^{* * *} \\
(3.444)\end{array}$ & $\begin{array}{l}0.003^{* * *} \\
(24.701)\end{array}$ & No \\
\hline 3 & $\begin{array}{l}0.032 * * * \\
(16.520)\end{array}$ & $\begin{array}{l}0.575^{* * *} \\
(6.331)\end{array}$ & $\begin{array}{l}-1.682^{* * *} \\
(-3.655)\end{array}$ & $\begin{array}{c}0.011 * * * \\
(23.821)\end{array}$ & Yes \\
\hline Log likelihood ratio & \multicolumn{5}{|c|}{$12,966.620$} \\
\hline $\begin{array}{l}\text { Linearity LR test } \\
\text { Davies test }\end{array}$ & \multicolumn{5}{|c|}{$\begin{array}{c}4,765.332 \\
(0.000) \\
{[0.000]}\end{array}$} \\
\hline
\end{tabular}

Transition probabilities $p(i / j)$

\begin{tabular}{l|l|l|l|l|l}
\hline $\boldsymbol{p}_{11}$ & 0.97 & $\boldsymbol{p}_{\mathbf{2 1}}$ & 0.07 & $\boldsymbol{p}_{\mathbf{3 1}}$ & 0.00 \\
\hline $\boldsymbol{p}_{\mathbf{1 2}}$ & 0.03 & $\boldsymbol{p}_{\mathbf{2 2}}$ & 0.90 & $\boldsymbol{p}_{\mathbf{3 2}}$ & 0.06 \\
\hline $\boldsymbol{p}_{\mathbf{1 3}}$ & 0.00 & $\boldsymbol{p}_{\mathbf{2 3}}$ & 0.03 & $\boldsymbol{p}_{\mathbf{3 3}}$ & 0.94 \\
\hline
\end{tabular}

Note: ${ }^{* * *},{ }^{* * *}$ represents significance at the $10 \%, 5 \%$ and $1 \%$ level, $t$-stats are reported in parentheses. Source: Author's calculation based on data set of S\&P 500

Table 6: Regime properties

\begin{tabular}{l|c|c|c|c|c}
\hline & No. of obs. & Prob. & Duration & Mean & Variance \\
\hline Regime 1 & 1,931 & 0.648 & 40.23 & 0.00058 & 0.00006 \\
\hline Regime 2 & 759 & 0.255 & 12.24 & 0.00003 & 0.00015 \\
\hline Regime 3 & 287 & 0.964 & 19.13 & $\mathbf{- 0 . 0 0 1 3 4}$ & $\mathbf{0 . 0 0 0 7 5}$ \\
\hline
\end{tabular}

Source: Author's calculation based on data set of S\&P 500. 
Regime properties are presented in Table 6. As the table shows, regime 1 is the low-volatility regime of S\&P 500. Its variance is 0.00006 and mean is 0.00058 . It covers 1,931 observations with the highest probability of $64.8 \%$ and an average duration of 40 days. Regime 2 is the high-volatility regime with 759 observations and $25.5 \%$ probability. Its average duration is 12.24 days. The variance of the regime is 0.00015 , which is higher than the former, while its mean is 0.00003 , which is lower than the mean return of regime 1 .

Regime 3 turns out to be mainly the crash regime for S\&P 500 market. It incorporates the least number of observations as 287 and probability of $9.6 \%$. This period has an expectedly negative mean return of -0.00134 and highest variance of 0.00075 compared to regimes 1 and 2.

\section{Figure 2: Smoothed probabilities}
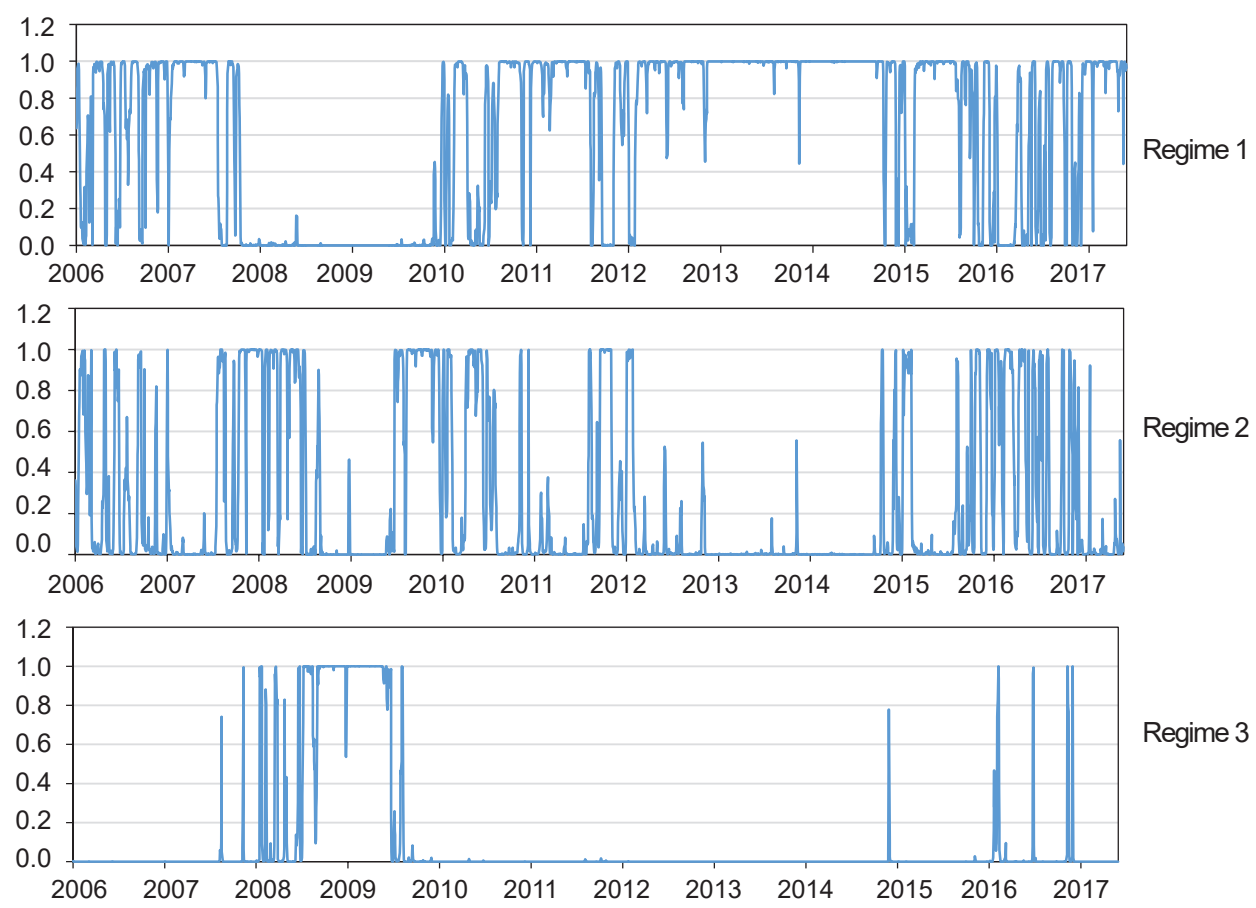

Source: Author's calculation based on data set of S\&P 500

Figure 2 shows the plot of smoothed probabilities for all of the three regimes. As discussed earlier, regime 3 turns out to be the crash regime; therefore, it covers mostly the crash period of 2007-2008 and some other events in 2014 (the Ottawa Shooting Incident in the capital of Canada), early 2016 (the UK's exit from EU) and late 2016 (Panama Papers). 


\section{Conclusion}

This study provides comprehensive evidence testing for the existence of herding effects in the US stock market under different market regimes. First, we used the approach of Bai and Perron (1998) to investigate herding in switching regimes. Then, we compared our findings with the findings of the MS approach.

In particular, our research reveals an interesting finding for herding when using the structural break approach of Bai and Perron (1998). The linear herding model incorrectly rejects herding in the US market, considering the whole data set. On the other hand, our findings from the Bai-Perron switching regression revealed strong evidence of herding in S\&P 500 (US) across different regimes. More specifically, the crisis regimes revealed significant evidence of herding. Moreover, the MS approach also confirmed our findings from the Bai-Perron approach. In the literature, there is mixed evidence of herding when linear approaches are used. Contrary to that, the findings of the non-linear models provide the same results of herding prevalence in crisis periods because of their strength to capture the time-varying nature of the herding anomaly.

We expect that our findings may provide an insight into traders. The impact of herding on the asset allocation process is important. When there is a correlated trading pattern, the benefits from diversification of assets may be reduced for investors and that leads to market inefficiency. Therefore, while constructing their portfolio, investors should take the significant impact of herding on the asset allocation process into consideration.

\section{References}

Bai, J., Perron, P. (1998). Estimating and Testing Linear Models with Multiple Structural Changes. Econometrica, 66(1), 47-78, https://doi.org/10.2307/2998540

Bai, J., Perron, P. (2003). Computation and Analysis of Multiple Structural Change Models. Journal of Applied Econometrics, 18(1), 1-22, https://doi.org/10.1002/jae.659

Balcilar, M., Demirer, R., Hammoudeh, S. (2013). Investor Herds and Regime-switching: Evidence from Gulf Arab Stock Markets. Journal of International Financial Markets, Institutions and Money, 23, 295-321, https://doi.org/10.1016/j.intfin.2012.09.007

Bekiros, S., Jlassi, M., Lucey, B. et al. (2017). Herding Behavior, Market Sentiment and Volatility: Will the Bubble Resume? The North American Journal of Economics and Finance, 42, 107-131, http://doi.org/10.1016/j.najef.2017.07.005 1062-9408

BenSaïda, A. (2017). Herding Effect on Idiosyncratic Volatility in US Industries. Finance Research Letters, 23, 121-132, http://doi.org/10.1016/j.frl.2017.03.001 1544-6123

Blasco, N., Corredor, P., Ferreruela, S. (2012). Does Herding Affect Volatility? Implications for the Spanish Stock Market. Quantitative Finance, 12(2), 311-327, https://doi.org/10.10 80/14697688.2010.516766 
Cakan, E., Balagyozyan, A. (2014). Herd Behaviour in the Turkish Banking Sector. Applied Economics Letters, 21(2), 75-79, https://doi.org/10.1080/13504851.2013.842629

Caparrelli, F., D'Arcangelis, A. M., Cassuto, A. (2004). Herding in the Italian Stock Market: a Case of Behavioral Finance. The Journal of Behavioral Finance, 5(4), 222-230, https://doi. org/10.1207/s15427579jpfm0504_5

Chang, E. C., Cheng, J. W., Khorana, A. (2000). An Examination of Herd Behavior in Equity Markets: An International Perspective. Journal of Banking \& Finance, 24(10), 1651-1679, https://doi.org/10.1016/S0378-4266(99)00096-5

Chiang, T. C., Zheng, D. (2010). An Empirical Analysis of Herd Behavior in Global Stock Markets. Journal of Banking \& Finance, 34(8), 1911-1921, https://doi.org/10.1016/j. jbankfin.2009.12.014

Choi, N., Sias, R. W. (2009). Institutional Industry Herding. Journal of Financial Economics, 94(3), 469-491, https://doi.org/10.1016/j.jfineco.2008.12.009

Christie, W. G., Huang, R. D. (1995). Following the Pied Piper: Do Individual Returns Herd around the Market? Financial Analysts Journal, 51(4), 31-37, https://doi.org/10.2469/faj. v51.n4.1918

Cingl, L. (2013). Does Herd Behaviour Arise Easier Under Time Pressure? Experimental Approach. Prague Economic Papers, 22(4), 558-582, https://doi.org/10.18267/j.pep.468

Davies, R. B. (1987). Hypothesis Testing when a Nuisance Parameter is Present only under the Alternative. Biometrika, 74(1), 33-43, https://doi.org/10.1093/biomet/74.1.33

Demirer, R., Kutan, A. M., Chen, C.-D. (2010). Do Investors Herd in Emerging Stock Markets?: Evidence from the Taiwanese Market. Journal of Economic Behavior \& Organization, 76(2), 283-295, https://doi.org/10.1016/j.jebo.2010.06.013

Economou, F., Kostakis, A., Philippas, N. (2011). Cross-Country Effects in Herding Behaviour: Evidence from Four South European Markets. Journal of International Financial Markets, Institutions and Money, 21(3), 43-460, https://doi.org/10.1016/j.intfin.2011.01.005

Fama, E. F. (1965). The Behavior of Stock-market Prices. The Journal of Business, 38(1), 34-105, https://doi.org/10.1086/294743

Gleason, K. C., Mathur, I., Peterson, M. A. (2004). Analysis of Intraday Herding Behavior among the Sector ETFs. Journal of Empirical Finance, 11(5), 681-694, https://doi.org/10.1016/j. jempfin.2003.06.003

Goyal, A., Santa-Clara, P. (2003). Idiosyncratic Risk Matters! The Journal of Finance, 58(3), 975-1007, https://doi.org/10.1111/1540-6261.00555

Grinblatt, M., Titman, S., Wermers, R. (1995). Momentum Investment Strategies, Portfolio Performance, and Herding: A Study of Mutual Fund Behavior. The American economic Review, 85(5), 1088-1105. Available at: https://www.jstor.org/stable/i352629

Hamilton, J. D. (1990). Analysis of Time Series Subject to Changes in Regime. Journal of Econometrics, 45(1-2), 39-70, https://doi.org/10.1016/0304-4076(90)90093-9

Hwang, S., Salmon, M. (2004). Market Stress and Herding. Journal of Empirical Finance, 11(4), 585-616, https://doi.org/10.1016/j.jempfin.2004.04.003 
Kim, K. A., Nofsinger, J. R. (2005). Institutional Herding, Business Groups, and Economic Regimes: Evidence from Japan. The Journal of Business, 78(1), 213-242, https://doi.org/10.1086/426524

Klein, A. C. (2013). Time-variations in Herding Behavior: Evidence from a Markov Switching SUR Model. Journal of International Financial Markets, Institutions and Money, 26, 291-304, https://doi.org/10.1016/j.intfin.2013.06.006

Lakonishok, J., Shleifer, A., Vishny, R. W. (1992). The Impact of Institutional Trading on Stock Prices. Journal of Financial Economics, 32(1), 23-43, https://doi. org/10.1016/0304-405X(92)90023-Q

Markowitz, H. (1952). Portfolio Selection. The Journal of Finance, 7(1), 77-91, https://doi. org/10.1111/j.1540-6261.1952.tb01525.x

Nofsinger, J. R., Sias, R. W. (1999). Herding and Feedback Trading by Institutional and Individual Investors. The Journal of Finance, 54(6), 2263-2295, https://doi. org/10.1111/0022-1082.00188

Sias, R. W. (2004). Institutional Herding. The Review of Financial Studies, 17(1), 165-206, https://doi.org/10.1093/rfs/hhg035

Tan, L., Chiang, T. C., Mason, J. R. et al. (2008). Herding Behavior in Chinese Stock Markets: An Examination of A and B Shares. Pacific-Basin Finance Journal, 16(1-2), 61-77, https://doi.org/10.1016/j.pacfin.2007.04.004

Walter, A., Weber, M. F. (2006). Herding in the German Mutual Fund Industry. European Financial Management, 12(3), 375-406, https://doi. org/10.1111/j.1354-7798.2006.00325.x

Wermers, R. (1999). Mutual Fund Herding and the Impact on Stock Prices. The Journal of Finance, 54(2), 581-622, https://doi.org/10.1111/0022-1082.00118 